\title{
REQUEST REALIZATIONS OF INDONESIAN ESP LECTURERS
}

\author{
Arif Nugroho \\ State Islamic Institute of Surakarta - Indonesia \\ arifnuugroho@gmail.com
}

\begin{abstract}
Drawing on the Speech Act theory, the present study endeavored to delineate the most frequently used request strategies by Indonesian English for Specific Purposes lecturers. In addition, it examined the involvement of situational variables of social distance, power, and imposition on the choice of their strategies. Another objective has been to reveal the reasons why the lecturers choose such strategies. To this end, a descriptive approach was adopted by employing Discourse Completion Test questionnaire and semi-structured interview to gather the data fromtwenty-eightESP lectures teaching at some different departments who werepurposively selected as the participants in this study. The results of the questionnaire illustrated that the participants made use of conventionally indirect expressions $(81.2 \%)$ for requests more frequently than other strategies. The semi-structured interview figured out that the participants' reason of utilizing conventionally indirect strategy was due to the cultural factors. Moreover, the situational variables of social distance, power, and imposition slightly affected the participants' choice of requests, but they had some influences on determining the degree of politeness. Furthermore, the analyzed data revealed the fact that first language culture, urgency of the requests, and physical attractiveness also influenced the participants' choice of request strategies.
\end{abstract}

Keywords: request realization,request strategies, situational variables, Indonesian ESP lectures

\section{INTRODUCTION}

The issue of communicative competence has been challenging and debatable for the researchers, experts, and linguists. The definition and context of communicative competence evolves almost in the recent fifty years. Nowadays, communicative competence is becoming an interesting issue in second language acquisition, even some people called it as the $21^{\text {st }}$ century skill. In fact, foreign language education has been devoted to the learning of grammar and vocabulary for years. Learners are frequently taught the structures of language and required to memorize as much as words of the language. The communicative function of language, as the result, seems to be put aside (Octactepe and Sanal, 2019). However, in the 1970s, Richards and Rodgers (1986) introduced a new approach called Communicative Language Teaching (CLT) which more emphasizes on the use of the language in real communication. This approach initiates the highlight of pragmatic competence in second language acquisition contexts and some research areas.

However, coming from the country having limited exposures to English language except in the classroom, the Indonesian students may encounter difficulties in their intercultural communication. According to Farashaiyan and Muthusamy (2016), 
the main problem that foreign language learners face in their intercultural communication is pragmatic-oriented. Similarly, Octactepe (2012) argues that foreign language learners have difficulty in developing pragmatic competence and communicating appropriately in different social interactions due to their limited knowledge of the cultural values and norms of the target language culture.As highlighted by Setyo, Suharsono, and Purwati (2018) teaching students a foreign language cannot be separated with its culture and knowledge of language use. It is essential for them to be equipped with the appropriate use of target language speech acts in learning foreign language pragmatic competence. Thus, researches and studies on the area of pragmatic competence, especially in the context of language teaching, have to be carried out as inputs to the teaching practitioners.

Pragmatic competence is closely related, even cannot be separated, from speech acts theory. One of the speech acts that is important in our communication is requesting. It is useful and happen often in everyday speech acts, particularly among new learners of language. Communication often start with a request, for instances, students make requests to their teachers, employers make requests to their boss, children make requests to their parents, etc. Compared to other types of speech acts, the illocutionary meaning of requests has been the most frequently researched in foreign language studies. When realizing a request, of course, the speakers want their requests are fulfilled by the hearers. That is why, the speakers consider the appropriate strategy when making a request. In addition, the choice of request strategies is generally influenced by situational variables; social distance, power, and imposition.

The well-known request strategy classification is under Cross-Cultural Speech Act Realization Project (CCSARP) by Blum-Kulka and Olshtain (1984). In general, there are three strategies; direct, conventionally indirect, and non-conventionally indirect. The direct request means the illocutionary force of the request is indicated in the utterance by grammatical, lexical, or semantic items which is expressed as imperatives, performatives, and want statements. For example, with regard to a situation in which the speaker asks to close a door, he said, "Close the door." or "You must close the door." Conventionally indirect request, in other direction, means the illocutionary force of the request by using fixed linguistic conventions which expresses as suggestory formulae and query preparatory questions, for instance, "What about closing the door?" or "Could you please close the door?". Last but not least, the non-conventionally indirect request means the utterance contains partial reference to object or element needed to implement the act. The examples are "The door is open" or "There is a drought in here". 
Furthermore, in realizing requests, the speakers are influenced by situational variables of social distance, power, and imposition (Brown and Levinson, 1987). The term social distance refers to the degree of familiarity and intimacy between interlocutors which can be determined by how well they know each other and whether they like each other. When the interlocutors are having close relation, they tend to have low degree of social distance, and vice versa. Then, power refers to the close relationship between interlocutors which is including social status, age, gender, ethnic identity, and institutionalized role. Moreover, the terms imposition refers to how great request the interlocutors make. A great rank of imposition will occur if the speaker is asking for a big favor, while a small rank of imposition will be existing when the scope of the request is small.

As mentioned earlier, in acquiring foreign language which is in this case is English, the learners have to extensively advance their pragmatic competence. Indonesian government has developed the English curricula that exposes the teachers to pay more attention to the use of English as a means of communication, which theoretically requires them to acquire pragmatic knowledge. English teachers are supposed to integrate the grammar principle into communicative framework (Sofyan and Suriya, 2017). Hence, the English teachershave to facilitate their students to learn pragmatics to enable the students to use language appropriately without leaving the essential use of correct grammar. They probably are the only resource to whom Indonesian EFL learners rely on to develop their pragmatic knowledge. Consequently, they should acquire adequate knowledge of pragmatics and language use.

However, the issue of English teachers' pragmatic knowledge slightly attracts the intentions of researchers, particularly Indonesian linguists. Most of the researches have concerned on investigating pragmatic aspects from the learners' point of views. Hence, following up some previous studies, the present study attempts to delineate the most frequently used request strategy by Indonesian ESP lecturers. Further, it examines how situational variables of social distance, power, and imposition influence their choice of request strategies. In addition, their reasons of using such strategies are also revealed. The participants' request strategies are classified based on Blum-Kulka and Olsthain's Cross-Cultural Speech Act Realization Project (CCSARP). This study, furthermore, is contributing to the enhancement of pragmatic theories in which the appropriate use of language is the main concern. Although the study is focusing on the acts of requesting, the findings are hopefully showing the portraits of Indonesian ESP lecturers' pragmatic knowledge. Finally, the findings are also expected to raise their awareness of the importance of pragmatic competence leading to their incorporation of this area in teaching practices. 


\section{METHOD}

To reach an in-depth description, the present study employed descriptive qualitative approach as the research design. It allows the researcher to describe the request strategies realized by Indonesian ESP lecturers and reveals the involvement of situational variables as well as their reasons in choosing the strategies. The descriptive qualitative approach is frequently applied by implementing the technique of searching, collecting, classifying, analyzing, and drawing conclusion.

The present study was conducted at a language institution at one of private universities in Malang, East Java, Indonesia. The population were all ESP lecturers teaching at nine faculties and about thirty-four departments in the university. Among them, the researcher purposively selected twenty-eight lecturers as the participants of this study. The selection was based on the educational background and the length of working. They graduated from English language teaching program, so it is assumed that they already have adequate knowledge in language grammar and oral communication. They were teaching in some faculties; i.e. Teacher Training and Education (8 lecturers), Social and Political Sciences (6 lecturers), Psychology (2 lecturers), Economics and Business (5 lecturers), Engineering (3 lecturers), Agriculture and Animal Husbandry (2 lecturers), and Law (2 lecturers).

The data were collected through two main instruments; Discourse Completion Test (DCT) questionnaire and semi-structured interview. The DCT questionnaire was employed to delineate the request strategies used by the participants and the involvement of social distance, power, and ranking in their choice of the strategies. DCT questionnaire is considered as a pragmatic test which constitutes an effective method to collect evidence of participants' speech acts. The DCT questionnaire used in this study consisted of twelve items and validated by an expert in linguistic studies. The situational variables of social distance, power, and imposition are randomly included in the twelve items as seen in Table 1. Before the DCT was administered, it was piloted to twenty-one students of graduate program in English language teaching. In the DCT questionnaire, a situational description is provided, and the participants are required to put their responses in the given blank spaces based on their roles described in the situation.Furthermore, a semi-structured interview was administered to figure out the participants' reasons in using the request strategies as well as how situational variables assembled in their requests. Five participants were selected in the interview phase based on their distribution of request strategies in their DCT questionnaires. They were asked some questions based on their responses in terms of their reasons and consideration of situational variables. The data obtained from interview were transcribed and coded as the basis to draw the conclusion.

Table 1. The Distribution of Situational Variables in DCT Questionnaire 


\begin{tabular}{lcc}
\hline \multicolumn{1}{c}{ Situation } & $\begin{array}{c}\text { Social } \\
\text { Factor }\end{array}$ & Item \\
\hline asking his colleague to borrow a textbook & Equal & 6 \\
asking his fellow colleague to help in a project & & 9 \\
borrowing a car to a very close neighbor & & 12 \\
\hline asking permission to a boss to join a conference & Speaker has a & 3 \\
asking a direction to a father's friend & lower status & 8 \\
asking permission to a boss to attend a brother's wedding & & 10 \\
\hline asking a shop assistant to find suitable size of t-shirt & Speaker has a & 4 \\
asking a student to take pictures & higher status & 5 \\
asking a waiter to give more water & & 7 \\
\hline asking his new neighbor to turn down a music volume & Strangers & 1 \\
borrowing a pen from a person who is not familiar with & & 2 \\
asking a teenager in the street to show direction & & 11 \\
\hline
\end{tabular}

The data collected from the participants by means of DCT questionnaire and semi-structured interview were analyzed through some stages. Firstly, the data in form of the participants' responses were kindly categorized into request strategies by referring to the theory of request strategies classification (CCSARP) by Blum-Kulka and Olshtain. The frequency of each strategy employed by the participants was then identified. The distribution of all request realization across all situations was also described to identify if the strategies are significantly different. Secondly, an in-depth analysis of how the situational variables of social distance, power, and imposition was conducted by deliberately analyzing the strategies given by the participants and relating them to the situational variables written in each item of DCT questionnaire. In addition, the transcribed result of interviews was kindly presented and followed by the analysis on the participants' reasons in choosing their request strategies.

\section{FINDINGS AND DISCUSSION}

\section{The most frequently used request strategies by Indonesian ESP lecturers}

Twenty-eight participants have realized 336 requests through 12 items listed in the DCT questionnaire. They applied direct, conventionally indirect, and non-conventionally indirect as their request strategies. The three strategies appeared, however, it was found that the distribution among them was extremely different. From 336 request realizations, 6 utterances $(1.7 \%)$ were considered as data biases; 1 blank response, in which the participant did not give utterance, and 5 responses did not belong to the acts of requesting. For instance, the participant only wrote "Excuse me, boss", which the utterance only expressed a greeting to the hearer and did not contain requesting act.Another example was the utterance "Go to my neighbor house and ask him to turn down the music volume”, which explained what would be done by the participant 
instead of giving a request when he was required to ask his neighbor to turn down his music volume. Further, the most frequently used strategy by the participants was conventionally indirect strategy ( 273 or $81.2 \%$ ) with query-preparatory as its substrategy. The less frequent strategy used by the participants was direct strategy (41 or $12.2 \%$ ) and the least frequent was non-conventionally indirect strategy (16 or $4.7 \%$ ). The distribution of request strategies could be seen in Table 2.

Table 2. Request strategies used by Indonesian ESP lecturers

\begin{tabular}{lccc}
\hline \multicolumn{1}{c}{ Strategies } & N/336 & Percentage (\%) \\
\hline Direct request & 41 & 12.2 \\
\hline Conventionally indirect request & 273 & 81.2 \\
\hline Non-conventionally indirect request & 16 & 4.7 \\
\hline
\end{tabular}

Table 2 showed that the most frequently used strategy by the participants in giving requests was conventionally indirect strategy. For instance, in situation 2 where the participants were asked to lend a pen from a person whom they were not familiar with, one of them made a request by suggesting, "Hello! I forget to bring my pen. How about borrowing yours?". Another example was given in responding to situation 1 in which they are required to make a request to their neighbor to turn down his music volume since it was late night, one of them said, "Could you please turn down your music volume? I have to finish my work.". Similarly, in responding to situation 3 in which the participants had to ask a permission to their boss to join an English conference, one of them said, "Pardon me, sir. There is a conference that I'd like to join very much. I need your permission concerning to this. So, may I join the conference? It does not disturb my teaching schedule anyway."

Further, direct strategy was the less frequent request strategy used by the participants. From 336 request realizations obtained from DCT questionnaire, 41 of them were made by using direct strategy. For example, in responding to situation 6 in which the participants were asked to borrow a textbook from their colleague, one of them said, "Lend me your textbook, please.". In the similar direction, the participants employed direct strategy when being asked in situation 7 where they were requested to ask a waiter of a restaurant to give some additional water. One of them said, "A glass of water please". Another example was a response to situation 5 which a participant said, "You have to help me writing my ESP book" when he was required to make a request to his fellow colleague to help him writing a project.

Moreover, the least frequent strategy utilized by the participants was nonconventionally indirect strategy. There were only 16 request utterances realized by using this strategy. A participant in this study said, "The choices of T-shirt are very limited in size. No one is suitable for $m e$ " when responding to situation 4 where the participants were asked to give a request to a shop assistant to find a suitable size of tshirt while shopping. In the same way, when the participants were required to ask their 
neighbor to turn down music volume as described in situation 1, one of them said, "Sorry, your music deafens my ears".

The present study reveals that conventionally indirect request is the most frequently used strategy by the participants in realizing their requests. According to Brown and Levinson, mentioned in Dittrich and Johansen and Kulinskaya (2011), using a more indirect form of request will lower the face threat. An indirect request seems more polite than an explicit request. This statement is seemly supported by the finding of this study in which the participants employed indirect requests instead of choosing the direct one. As stated by Brown and Levinson, the participants try to consider themselves as a polite person in the eyes of other people. The most influenced factor of the choice of indirect request by the participants is their cultural backgrounds since they come from Indonesia, a country representing the eastern culture. The culture of being polite to anyone, anytime, and anywhere seems to be the most dominant consideration in choosing indirect request strategy.

In terms of this, the finding of this study is in consistent to an investigation conducted by Salvesen (2015). She examined the politeness strategies in requesting acts by Norwegian learners of English. The result showed that the Norwegian learners of English dominantly used indirect strategies in making their requests. However, the distribution of the indirect strategies is not extremely different compared to another strategy, i.e. direct requests. It is different to what this study found related to the distribution of the request strategies. In this study, conventionally indirect strategy is quite dominant than other request strategies used by the Indonesian ESP lecturers. They even response all requests written in the twelve situations in DCT questionnaire by using conventionally indirect strategy.

In the same direction, the result of this study in terms of the most frequently used request strategy is also similar with the result of the study conducted by Daskalovka, Ivanoska, and Kusevska (2016) examining the request strategy used by EFL learners in Macedonia. They used role play and DCT questionnaire as the instruments in collecting the data. Similar with this study, the participants responses were analyzed according to the classification of request strategies by Blum-Kulka et.al (1989). The data analysis resulted in the same finding with this study in which the most frequently used types of request strategies were query preparatory which belonged to the group of conventional indirect strategy.

Nevertheless, the result of this study is in contrast with the study result conducted by Bonyadi and Yazdanfar (2016). They conducted a comparative study to explore the request strategies used in daily interactions of Persian and English speakers by analyzing Persian TV series that were observed and the request utterances were transcribed. The results revealed that the speakers of both languages opted the direct requests as their most frequently used strategy in their daily interactions. According Bonyadi and Yazdanfar (2016), the preference of direct strategies by the speakers of a 
language cannot be taken as a proof that they are not polite. It significantly depends on the speakers' cultural backgrounds and the habit of using language in their daily interactions. Moreover, the social meaning implied by a linguistic behavior should also be considered. The members of two cultures may not necessarily consider the directness and indirectness similarly. Although indirectness and politeness are usually related, their social meaning may be different in different cultures.

\section{The involvement of situational variables}

Looking at each participants' request realization more intentionally as presented in Table 3, although the description of the roles in each situation had different degree of situational variables of social distance, power, and imposition, conventional indirect strategy was the most utilized one by the participants even in all twelve situations. They follow the same trend; conventionally indirect, direct, and non-conventionally indirect strategies were the first, second, and third most frequently used one. This indicated that the three situational variables of social distance, imposition, and power had not that much effect on the participants' request realizations.

Table 3. The Detail Distribution of the Participants'Request Strategiesin each Situation

\begin{tabular}{clcc}
\hline Situations & \multicolumn{1}{c}{ Strategy Types } & N/330 & Percentage \\
\hline 1 & Most Direct & 4 & 14.2 \\
& Conventionally indirect & 21 & 75.0 \\
& Non-conventionally indirect & 3 & 10.7 \\
\hline 2 & Most Direct & 1 & 3.5 \\
& Conventionally indirect & 26 & 92.8 \\
& Non-conventionally indirect & 1 & 3.5 \\
\hline 3 & Most Direct & 4 & 14.2 \\
& Conventionally indirect & 20 & 71.4 \\
& Non-conventionally indirect & 4 & 14.2 \\
\hline 4 & Most Direct & 2 & 7.1 \\
& Conventionally indirect & 24 & 85.7 \\
& Non-conventionally indirect & 1 & 3.5 \\
\hline 5 & Most Direct & 2 & 7.1 \\
& Conventionally indirect & 25 & 89.2 \\
& Non-conventionally indirect & 1 & 3.5 \\
\hline 6 & Most Direct & 4 & 14.2 \\
& Conventionally indirect & 24 & 85.7 \\
& Non-conventionally indirect & 0 & 0 \\
\hline 7 & Most Direct & 9 & 32.1 \\
& Conventionally indirect & 16 & 57.1 \\
& Non-conventionally indirect & 3 & 10.7 \\
\hline 8 & Most Direct & 1 & 3.5 \\
& Conventionally indirect & 26 & 92.8 \\
\hline
\end{tabular}




\begin{tabular}{clcc}
\hline & Non-conventionally indirect & 0 & 0 \\
\hline \multirow{3}{*}{9} & Most Direct & 3 & 10.7 \\
& Conventionally indirect & 24 & 85.7 \\
& Non-conventionally indirect & 0 & 0 \\
\hline \multirow{2}{*}{10} & Most Direct & 6 & 21.4 \\
& Conventionally indirect & 17 & 60.7 \\
& Non-conventionally indirect & 3 & 10.7 \\
\hline \multirow{2}{*}{11} & Most Direct & 4 & 14.2 \\
& Conventionally indirect & 24 & 85.7 \\
& Non-conventionally indirect & 0 & 0 \\
\hline \multirow{2}{*}{12} & Most Direct & 1 & 3.5 \\
& Conventionally indirect & 26 & 92.8 \\
& Non-conventionally indirect & 0 & 0 \\
\hline
\end{tabular}

The distribution of request strategies in all situations in DCT questionnaire are similar. The participants utilize conventionally indirect as their strategy in realizing requests, whereas, the DCT questionnaire has been involved with situational variables of social distance, power, and imposition in all descriptions of the situations. The data analysis of the participants' requests, supported by the data obtained from interviews, confirms that the participants seem to neglect the involvement of the situational variables. They choose conventionally indirect strategy because they want to be seen as a polite person no matter talking to anyone, anywhere, anytime, and in any situation. They greatly affected by the eastern culture paradigm which requires them to be a polite person. Therefore, the situational variables of social distance, power, and imposition have slightly affected their choice of request strategies.

This finding is in consistent with the result of the study conducted by Sofyan and Suriya (2017) that investigates the English instructors' pragmatic awareness and realization in requests. They described and elaborated the pragmatic awareness and realization of request speech acts among 12 representations of non-native English speakers by means of DCT questionnaire and role play. The result of the study shows that the participants were slightly aware of the situational variables; power relation is the social factor that mostly influenced the choices of request strategies in oral production of requests. This finding is quite similar with what this study found in terms of the involvement of the situational variables. This might be caused by the lack of participants' awareness to the roles of social distance, power, and imposition described in DCT questionnaire.

Likewise, the result of this study confirms the result of the study conducted by Farashaiyan and Muthusamy (2016). They examined the effects of the situational factors of social distance, power, and imposition on the international postgraduate students' choice of request and apology strategies. Similar to this study, DCT 
questionnaire and semi-structured interview were used as the data instruments. The result of the study shows that the situational factors of social distance, power, and imposition did not affect the participants' choice of request strategies, but they had some influences some influences on the use of mitigating strategies in different situations.

\section{The Indonesian ESP lecturers reasons of using conventionally indirect requests}

As conventionally indirect strategy was the most utilized strategy in realizing requests by the participants, it made the researcher wondering and excitedly wanted to know why they massively used this strategy. The results of interview to the five chosen participants revealed the answer of this question. The participants tended to use conventionally indirect strategy primarily because the influence of cultural and first language backgrounds. They want to be seen as a polite person since they live in an eastern culture as a participant said when being asked about their reason.

"I am talking to my boss and I know his position in the office. I am his sub-ordinate. I believe that by using more proper and polite words will really touch his feeling, and maybe he would grant me a permission to join conference. Due to the very close social distance, therefore, I perform the politest strategy of making request."

In similar direction, a participant stated that his reason in using conventionally indirect strategy in his request realization was feeling comfortable. He considered that being polite to anyone, even to strangers was a must in order to make the interlocuters fell comfortable with him. Completely he said,

"When speaking to anyone, I think we have to be polite, even to the strangers. Being polite is essential to make our interlocutors feel comfortable with us. They would potentially fulfill our request sincerely". Additionally, he also stated,

"Our culture forces us to behave politely to anyone. This is what I consider when making request to other people, though they are in the same age and social status with me. I always try to use the politest words and sentences so that my interlocutors feel comfortable and not being intimidated, including to my colleague in the office".

Interestingly, the results of interviews had also revealed that there were other factors contributing to the choices of the participants' request strategies. These factors were urgency of request and physical attractiveness. One of the participant stated that he tended to employ direct strategy when it was an urgent request. According to him, he needed to do it to make the request fulfilled immediately. Direct request was usually utilized when requesting to the person whom familiar with such as sub-ordinates, employees, students, etc. In addition, the physical attractiveness, specifically how the interlocutors dressed, was also give an influence on the choice of the participants' 
request strategies. The interview results found that the participants tended to use conventionally indirect strategy when requesting to a well-dressed and polite person. They said that it was closely related to their first language backgrounds in which they live in eastern culture.

The findings resulted from DCT questionnaire and semi-structured interview shows that the Indonesian ESP lecturers mostly made use of the same strategies across all the situations, although the situations varied in terms of the three situational factors of the social distance, power, and imposition. In other words, they seemly did not pay enough attention to the mentioned factors. Therefore, it might be concluded that they were lack enough both pragma linguistic and sociopragmatic knowledge. The finding of the interview also supports the DCT questionnaire finding since the participants confess that they did not consider the situational variables involved in the twelve situations described in DCT when they were filling up the questionnaire. The most important thing they think is that they want to be seen as a polite person in realizing requests. Therefore, they employed conventionally indirect request as their most frequently used strategy.

\section{CONCLUSION}

This study indicates that pragmatic knowledge should be taught in Indonesian EFL context to avoid communication breakdowns. The researcher argues here that Indonesian ESP lecturers have to enhance their pragmatic awareness and help improve their students' pragmatic knowledge. As shown in this study, the Indonesian ESP lecturers mostly used conventionally indirect strategy in realizing their requests in almost all situations which indicates that they do not pay more attention to the involvement of situational variables of social distance, power, and imposition. Though the results presented here are positively contributing to the area of pragmatics, some limitations are observed. Future researches can advance this study by implementing instruments such as oral DCT questionnaire and role plays to obtain more naturally occurrence data. Moreover, the further researches are also strongly encouraged to consider variables of physical attractiveness and urgency of request in examining the most frequently used request strategies by a particular social group. Finally, since this study is focusing on the speech act of request, it is suggested that future researches take into account other types of speech acts as other variables.

\section{REFERENCES}

Blum-Kulka, S \& Olshtain, E. (1984). 'Requests and apologies: A crosscultural study of speech act realization patterns' (CCSARP). Applied Linguistics, Vol. 5No. 3: 197213. 
Bonyadi, A., \& Yazdanfar, S. (2016). Request strategies in everyday interactions of Persian and English speakers. Sage Publication, 1-11. doi: 10.1177/2158244016679473sgo.sagepub.com

Brown, P. \& Levinson, S. C. (1987). Politeness: Some Universals in Language Usage. Second Edition. Cambridge: Cambridge University Press.

Daskalovska, N., Kusevska, M., \& Ivanovska, B. (2016). The use of request strategies by EFL learners. Procedia - Social and Behavioral Science, 232(2016), 55-61. doi: 10.1016/j.sbspro.2016.10.015

Dattrich, W.H., Johansen, T., \& Kulinskaya, E. (2011). Norms and situational rules of address in English and Norwegian speakers. Journal of Pragmatics, 43(15), 38073821 .

Farashaiyan A., \&Muthusamy P. (2016). Situational variations in request and apology realization strategies among international postgraduate students at Malaysian universities. Journal of English Language Teaching, 9(3), 181-196. doi: 10.5539/elt.v9n3p181

Octactepe, D. (2012). The development of conceptual socialization in international students: A language socialization perspective on conceptual fluency and social identity (advances in pragmatics and discourse analysis). Cambridge: Cambridge Scholars Publishing.

Octactepe, D., \& Sanal, M. (2019). Conceptual socialization in EFL contexts: A case study on Turkish EFL learners' request speech acts realization. Journal of Language and Linguistics Studies, 15(1), 376-399. doi: 10.17263/jlls.547766

Richards, J.C. \& Rodgers, S. T. 1986. Approaches and Methods in Language Teaching. Cambridge: CUP.

Salvesen, K. E. (2015) Politeness strategies in requests by Norwegian learners of English in comparison with native speakers of English. Hawai Pasific University TESOL Working Paper Series 13, 53-69. doi: http://www.hpu.edu

Setyo, R.C.Y., Suharsono, Purwati, O. (2018). The contribution of school culture to the learner success factors in e-learning. Journal on English as a Foreign Language, 8 (2), (149-169). Retrieved from http://e-journal.iainpalangkaraya.ac.id/index.php/jefl/article/viewFile/884/876 
Sofyan A., \& Suriya H. A. (2017). The relation between pragmatic awareness and realization of requests among non-native english intructors. English Education Journal, 7(3), 213-219. doi: http://journal.unnes.ac.id/sju/index.php/eej 